\title{
ANALISIS PENGENDALIAN PERSEDIAAN BAHAN BAKU UPAYA MEMINIMALKAN BIAYA PERSEDIAAN PADA PERUSAHAAN ELANG SEDERHANA DI KOTA PALEMBANG.
}

\author{
Iskandar Ali Alam ${ }^{1}$, Winarto Tandra ${ }^{2}$ \\ Fakultas Ekonomi dan Bisnis, Universitas Bandar Lampung \\ Jl. ZA Pagar Alam No. 26. Labuhan Ratu, Bandar Lampung. \\ Email : iskandar@ubl.ac.id; winartotandra@gmail.com
}

\begin{abstract}
ABSTRAK
Penelitian ini bertujuan untuk mengkaji lebih dalam tentang penggunaan metode Economic Order Quantity (EOQ) dalam mengendalikan bahan baku Perusahaan Elang Sederhana. Data penelitian ini adalah jumlah pembelian, jumlah persediaan, jumlah pemakaian bahan baku yang digunakan dalam proses produksi, serta biaya pemesanan dan biaya penyimpanan bahan baku.

Hasil penelitian didapatkan persediaan bahan baku yang optimal merupakan faktor penting dalam proses kelancaran produksi pada suatu perusahaan. Bahan baku ini dapat dikendalikan dengan menggunakan metode tertentu, salah satunya adalah metode Economic Order Quantity(EOQ) yang memiliki tingkat keakuratan perhitungan yang lebih baik dibandingkan dengan metode konvensional. Hasil penelitian didapatkan persediaan optimal bahan baku Sagu Rumbia menggunakan metode EOQ sebesar $17.249 \mathrm{~kg}$ dengan frekuensi pembelian sebanyak 36 kali, Safety Stock sebesar $4.084 \mathrm{~kg}$ dan ROP dilakukan pada saat bahan baku digudang sebesar 4.946kg dengan TIC Rp 124.200.000, sedangkan menggunakan metode konvensional pembeliaan bahan baku sebesar $4960 \mathrm{~kg}$ dengan frekuensi pembelian sebanyak 36kali dan safety stock sebesar $5000 \mathrm{~kg}$.

Kesimpulan dari penelitian ini adalah perhitungan menggunakan metode EOQ pada bahan baku sagu rumbia lebih efisien dibandingkan dengan metode konvensional. Hal ini terlihat dari hasil perbandingan TIC yang lebih efisien menggunakan metode EOQ sehingga mampu menghemat biaya dan mampu menambah keuntungan. Saran yang dianjurkan bagi menejemen Perusahaan Elang Sederhana adalah dengan menggunakan metode EOQ dalam proses pengendalian bahan baku perusahaan.
\end{abstract}

Kata Kunci : Economic Order Quantitty (EOQ), Persediaan Bahan Baku, Safety stock (SS), Reorder Point (ROP), Total Inventory Cost (TIC). 


\begin{abstract}
This study aims to examine more deeply the use of the Economic Order Quantity (EOQ) method in controlling the raw materials of the Elang Sederhana Company.the data of this study is the number of purchase, the amount of inventories, the amount of usage of raw materials used in production, as well a booking fee and the cost storage of raw materials.

Optimal of raw material supply is an important factor in the fluency of thr production process in a company. These raw materials can be controlled by using certain methods, one of that is a Economic Order Quantity (EOQ) method which has a better level calculation accuracy than conventional methods.

The result showed the optimal inventory of sago palm materials using EOQ method is $17.249 \mathrm{~kg}$ with frequency of purchase as 36 times, safety stock is $4.084 \mathrm{~kg}$ and the ROP done at the same time the raw material werehouse at $4.946 \mathrm{~kg}$ and TIC Rp. 124.200.000, while using the conventional method of buying raw materials of $4960 \mathrm{~kg}$ with a frequency of purchases of 36 times and a safety stock of 5000 $\mathrm{kg}$.

Conclusion from this research is the calculation method of EOQ in the counting raw materials sago palm more efficiently than with conventional methods. This can be prove from the result of the comparison TIC more efficient use EOQ method to save cost and is able to increase profits. Suggestion for menegement of Elang Sederhana company is to use EOQ method in processs of controlling raw materials companies.
\end{abstract}

Key Word : Economic Order Quantitty(EOQ), Raw Material Supply, Safety stock (SS), Reorder Point (ROP), Total Inventory Cost(TIC).

\section{PENDAHULUAN}

Perusahaan Elang Sederhana merupakan salah satu perusahaan yang bergerak di bidang industri yang melakukan pembuatan/produksi sohun di kota Palembang. Perusahaan ini berdiri sejak tahun 1989, Bahan baku pembuatan sohun adalah sagu rumbia. Dalam menjalankan produksinya, perusahaan elang sederhana membeli bahan baku secara konvensional (yang membeli tanpa ada perhitungan) sehingga perusahaan mengeluarkan dana lebih untuk bahan baku dan penyimpanan.

Setiap perusahaan harus dapat mengambil keputusan tentang kegiatan pengadaan persediaan barang pada perusahaan yang akan menimbulkan berbagai macam biaya, seperti biaya pembelian, biaya pemesanan, dan biaya penyimpanan. Dengan adanya biaya-biaya tersebut diperlukan adanya pengendalian persediaan yang memiliki fungsi untuk menyediakan persediaan yang sesuai dengan biaya minimal. Oleh karena itu, tingkat persediaan yang sesuai dapat dilakukan dengan menentukan jumlah pesanan yang ekonomis dengan tujuan untuk menentukan jumlah pesanan yang mampu memperkecil biaya pengadaan persediaan. Oleh sebab itu, diperlukan penggunaan metode Economic Order Quantity (EOQ) dalam menentukan persediaan yang optimal agar dapatmeminimalkan biaya persediaan maupun biaya-biaya lainnya.

Economic Order Quantity menurut Heizer dan Render (2015:92) merupakan sebuah teknik kontrol persediaan yang meminimalkan biaya total dari pemesanan dan penyimpanan. Dalam metode EOQ, terdapat perhitungan frekuensi pemesanan, safety stock, reorder point dan total inventory cost agar perusahaan mampu memperhitungkan persediaan yang optimal.

Perusahaan Elang Sederhana selalu menyediakan bahan baku untuk produksi. Persediaan total diperoleh dari persediaan akhir bulan sebelumnya ditambah dengan pembelian bahan baku oleh perusahaan. Dari data tersebut dapat dilihat bahwa perusahaan membutuhkan bahan baku sebesar $155.500 \mathrm{~kg}$ dalam satu tahun. Maka, perusahaan membutuhkan rata-rata $12.958 \mathrm{~kg}$ dalam satu bulan. Dengan Lead Time 2 hari untuk mengatasi ancaman keterlambatan bahan baku. Dari data tersebut, akan terlihat bahwa perusahaan mengalami kelebihan persediaan pada bulan Januari sebesar 2.000 $\mathrm{kg}$, bulan Februari $3.500 \mathrm{~kg}$, bulan Maret $1.000 \mathrm{~kg}$, bulan April $6.000 \mathrm{~kg}$, bulan Mei $9.000 \mathrm{~kg}$, bulan Juni $10.000 \mathrm{~kg}$, bulan Juli $11.000 \mathrm{~kg}$, bulan Agustus $14.000 \mathrm{~kg}$, bulan September $16.000 \mathrm{~kg}$, bulan Oktober 20.000 $\mathrm{kg}$, bulan November $21.000 \mathrm{~kg}$, dan bulan Desember $23.000 \mathrm{~kg}$. 
Berdasarkan permasalahan yang telah dipaparkan maka perumusan masalah pada penelitian ini adalah :

1. Berapa jumlah pembelian Sagu Rumbia yang optimal dengan menggunakan metode Economic Order Quantity(EOQ) pada Perusahaan Elang Sederhana?

2. Berapa frekuensi pemesanan bahan baku Sagu Rumbia yang optimal dengan menggunakan metode Economic Order Quantity pada Perusahaan Elang Sederhana?

3. Berapa jumlah persediaan pengaman bahan baku Sagu Rumbia yang optimal dengan menggunakan metode Economic Order Quantity pada Perusahaan Elang Sederhana?

4. Berapa jumlah Reorder Point persediaan bahan baku dengan menggunakan metode Economic Order Quantity (EOQ) pada Perusahaan Elang Sederhana?

5. Berapa besar total biaya persediaan jika menggunakan metode Economic Order Quantity (EOQ) pada Perusahaan Elang Sederhana?

Batasan masalah penelitian ini adalah : Untuk memfokuskan agar permasalahan yang diamati tidak meluas dan tidak menyimpang dari sasaran serta tema pokok permasalahan, maka diperlukan batasan - batasan masalah yakni :

1. Penelitian hanya di lakukan di Perusahaan Elang Sederhana.

2. Penelitian hanya memfokuskan pada persediaan bahan baku Sagu Rumbia yang di gunakan oleh Perusahaan Elang Sederhana

Menurut Agus Ristono (2013:2) Persediaan merupakan suatu teknik yang berkaitan dengan penetapan terhadap besarnya persediaan barang yang harus diadakan untuk menjamin kelancaran dalam kegiatan operasi produksi, serta menetapkan jadwal pengadaan dan jumlah pemesanan barang yang seharusnya dilakukan oleh perusahaan.

Menurut Heizer dan Render (2015:553), "Persediaan adalah menetukan keseimbangan antara investasi persediaan dan pelayanan pelanggan. Tujuan persediaan tidak akan pernah mencapai strategi berbiaya rendah tanpa manajemen persediaan yang baik".

Persediaan yang terdapat dalam perusahaan dapat dibedakan menurut beberapa cara. Dilihat dari fungsinya, menurut Heizer \& Render (2015 : 553). Persediaan dapat memiliki berbagai fungsi yang menambah fleksibilitas operasi

perusahaan. Keempat fungsi persediaan adalah sebagai berikut :

1. Untuk memberikan pilihan barang agar dapat memenuhi permintaan pelanggan yang diantisipasi dan memisahkan perusahaan dari fluktuasi permintaan. Persediaan seperti ini digunakan secara umum pada perusahaan ritel. 2. Untuk memisahkan beberapa tahapan dari proses produksi. Contohnya, jika persediaan sebuah perusahaan berfluktuasi, persediaan tambahan mungkin diperlukan agar bisa memisahkan proses produksi dari pemasok.

3. Untuk mengambil keuntungan dari potongan jumlah karena pembelian dalam jumlah besar dapat menurunkan biaya pengiriman barang.

4.Untuk menghindari inflasi dan kenaikan harga.

Ada pula fungsi persediaan yang lain. Fungsifungsi persediaan menurut Stevenson

dan Chuong(2014:181). Pesediaan dapat memiliki berbagai fungsi yang menambah fleksibilitas operasi perusahaan.

Beberapa fungsi persediaan adalah sebagai berikut:

1. Untuk memberikan pilihan barang agar dapat memenuhi permintaan

pelanggan yang diantisipasi dan memisahkan perusahaan dari fluktuasi

permintaan. Persediaan seperti ini digunakan secara umum pada perusahaan ritel. Persediaan ini dirujuk sebagai persediaan antisipasi karena disimpan untuk memuaskan permintaan yang diperkirakan yaitu, rata-rata.

2. Untuk memisahkan beberapa tahapan dari proses produksi. Perusahaan yang mengalami pola musiman dalam permintaan sering kali membangun persediaan selama periode pramusim untuk memenuhi keperluan yang luar biasa tinggi selama periode musiman.

3. Untuk memisahkan operasi. Secara historis, perusahaan manufaktur telah menggunakan persediaan sebagai penyangga antara operasi yang berurutan untuk memelihara kontinuitas produksi yang dapat saja terganggu oleh kejadian seperti kerusakan perlengkapan dan kecelakaaan yang menyebabkan sebagian operasi dihentikan sementara . 


\section{METODOLOGI PENELITIAN}

Perhitungan Economic Order Quantity (EOQ), Berdasarkan paparan dari Handoko (2000:340) perhitungan EOQ dapat dilakukan dengan rumus sebagai berikut:

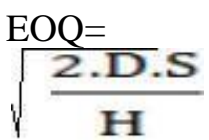

Keterangan:

$\mathrm{S}=$ biaya pemesanan per pesanan

$\mathrm{D}=$ pemakaian bahan periode waktu.

$\mathrm{H}=$ biaya penyimpanan per unit per tahun

Persediaan Pengaman ( safety stock)

Perusahaan dalam melakukan pemesanan suatu barang sampai barang datang memerlukan jangka waktu yang bisa berbeda beda setiap bulannya. Hal ini sering disebut dengan lead time.

Berdasarkan uraian Nafarin (2004:87) persediaan pengamanan (safety stock) adalah persediaan inti dari bahan yang harus dipertahankan untuk menjamin kelangsungan usaha.Persediaan pengaman tidak boleh dipakai kecuali dalam keadaan darurat, seperti keadaan bencana alam, alat pengangkut bahan kecelakaan, bahan dipasaran dalam keadaan kosong karena huru-hara, dan lain-lain. Persediaan pengaman bersifat permanent, karena itu, persediaan bahan baku minimal (persediaan pengaman) termasuk kelompok aktiva.

Untuk menghitung besarnya safety stock dapat menggunakan metode perbedaan pemakaian maksimum dan rata-rata. Dapat diformulasikan sebagai berikut:

Safety stock $=$ (Pemakaian Maksimum Pemakaian Rata-rata) x Lead Time

Titik Pemesanan Kembali atau Recorder Point (ROP)RecorderPoint memperhatikan pada persediaan yang tersisa digudang baru kemudian dilakukan pemesanan kembali.Hal ini dikarenakan adanya jangka waktu tunggu diantara pemesanan dengan datangnya pesanan, oleh karena itu pemakaian bahan selama pemesanan harus diperhitungkan.Pendapat dari Slamet (2007:161) didasarkan pada besarnya penggunaan bahan selama bahan dipakai dan besarnya safety stock.besarnya penggunaan bahan selama waktu pemesanan merupakan perkalian antara lamanya waktu pemesanan dan penggunaan rata-rata. Recorder point berdasarkan paparan diformulasikan sebagai berikut:

Recorder Point $=(\mathrm{LD} \times \mathrm{AU})+\mathrm{SS}$

Dimana:

$\mathrm{LD}=$ Lead Time atau waktu tunggu

$\mathrm{AU}=$ Average Unit atau rata-rata pemakaian selama satuan waktu menunggu.

SS = Safety Stock atau persediaan pengaman.

Total Biaya Persediaan atau Total Inventory

Cost (TIC) Dalam perhitungan biaya total persediaan, bertujuan untuk membuktikan bahwa dengan terdapatnya jumlah pembelian bahan baku yang optimal, yang dihitung dengan metode EOQ akan dicapai biaya total persediaan bahan baku minimal.

(TIC/TC) adalah sebagai berikut. Menurut

(Heizer \& Render)

Rumus dari TIC/TC: TIC/TC $=\mathrm{D} / \mathrm{Q} \mathrm{s}+\mathrm{Q} / 2 \mathrm{H}$

Dimana:

Q : Jumlah unit per pesanan

D : Permintaan tahunan dalam unit untuk

barang persediaan

$\mathrm{S}$ : Biaya pemasangan atau pemesanan untuk setiap pesanan

$\mathrm{H}$ : Biaya penyimpanan per unit per tahun

Kerangka Konseptual

1. Persediaan bahan baku pada Perusahaan Elang Sederhana menggunakan kebijakan perhitungan tradisional dalam penentuan persediaan bahan baku.

2. Berdasarkan metode konvensional, diketahui jumlah kebutuhan, jumlah pembelian, jumlah pemakaian, dan jumlah persediaan Perusahaan Elang Sederhana belum menghasilkan biaya yang minimal.

3. Menghitung jumlah pembelian yang paling ekonomis, kebutuhan bahan baku, frekuensi pembelian, safety stock dan reorder point dengan metodeEOQ.

4. Membandingkan hasil perhitungan metode konvensional dengan metode EOQ.

5. Menghitung dan membandingkan TIC konvensional dengan TIC EOQ.

6. Penggunaan metode EOQ menghasilkan biaya persediaan (TIC) yang minimal 
3. PEMBAHASAN

Pembelian Bahan Baku Sagu Rumbia

\begin{tabular}{|l|l|}
\hline \multicolumn{1}{|c|}{ Bulan } & Pembelian (kg) \\
\hline Januari & 14.000 \\
\hline Februari & 15.000 \\
\hline Maret & 13.500 \\
\hline April & 15.000 \\
\hline Mei & 15.000 \\
\hline Juni & 11.000 \\
\hline Juli & 15.000 \\
\hline Agustus & 15.000 \\
\hline September & 15.000 \\
\hline Oktober & 19.000 \\
\hline November & 16.000 \\
\hline Desember & 15.000 \\
\hline Jumlah & 178.500 \\
\hline Rata-rata Per Bulan & 14.875 \\
\hline Sumber : Data pen & \\
\hline
\end{tabular}

Sumber : Data pembelian bahan baku yang telah diolah

Berdasarkan informasi dari Tabel di atas Pembelian Bahan Baku Sagu Rumbia Perusahaan Elang Sederhana dapat diketahui jumlah total pembelian selama satu tahun yaitu sebesar $178.500 \mathrm{~kg}$ dengan rata-rata pembelian $14.875 \mathrm{~kg}$ perbulan. Untuk rata-rata pemakaian bahan baku sagu rumbia yang digunakan oleh perusahaan dalam melakukan produksi dapat diketahui sebesar $496 \mathrm{~kg}$.

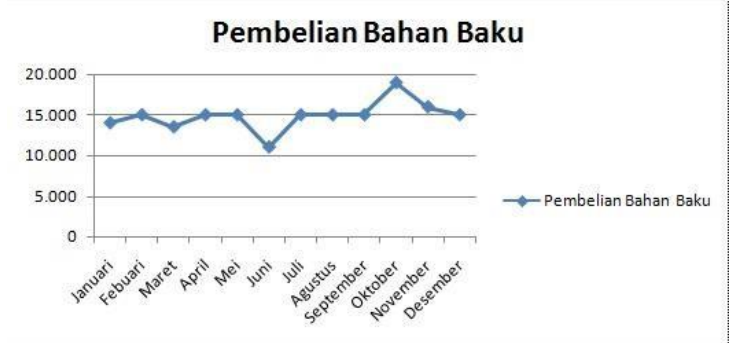

Pemakaian Bahan Baku Sagu Rumbia

\begin{tabular}{|l|l|}
\hline \multicolumn{1}{|c|}{ Bulan } & \multicolumn{1}{c|}{ Pemakaian $(\mathrm{kg})$} \\
\hline Januari & 12.000 \\
\hline Februari & 13.500 \\
\hline Maret & 11.000 \\
\hline April & 15.000 \\
\hline Mei & 12.000 \\
\hline Juni & 10.000 \\
\hline Juli & 14.000 \\
\hline Agustus & 12.000 \\
\hline September & 13.000 \\
\hline Oktober & 15.000 \\
\hline November & 15.000 \\
\hline Desember & 13.000 \\
\hline Jumlah & 155.500 \\
\hline Rata-rata Per Bulan & 12.958 \\
\hline Rata-rata per hari & 431 \\
\hline
\end{tabular}

Sumber :Data pemakaian bahan baku yang telah diolah

Berdasarkan Tabel 4.2 Pemakaian Bahan Baku Sagu Rumbia, diperoleh informasi jumlah pemakaian bahan baku selama satu tahun sebesar $155.500 \mathrm{~kg}$ dengan pemakaian ratarata perbulan senilai $12.958 \mathrm{~kg}$ perbulannya. Perusahaan Elang Sederhana dalam tiap kali melakukan pemesanan mengeluarkan biaya pemesanan.Biaya pemesanan yang dikeluarkan oleh perusahaan berupa biaya bongkar dan biaya telepon.

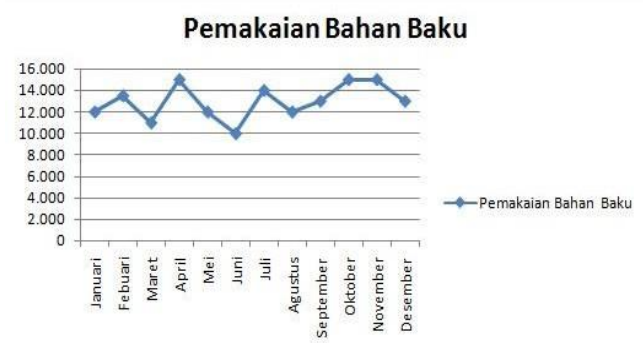


Biaya Pemesanan Bahan Baku Sagu Rumbia

\begin{tabular}{|l|l|}
\hline Jenis Biaya & Jumlah \\
\hline Biaya Angkutan & Rp. 3.000.000 \\
\hline Biaya Bongkar Muat & Rp. 150.000 \\
\hline Biaya Telfon & Rp. 50.000 \\
\hline Total Biaya & Rp. 3.200.000 \\
\hline
\end{tabular}

Sumber : Data Biaya Pemesanan yang telah diolah

Biaya Pemesanan Bahan Baku Sagu Rumbia, dapat diketahui bahwa biaya setiap kali melakukan pemesanan sebesar Rp 3.000.000 untuk biaya transport, untuk biaya bongkar muat sebesar Rp 150.000 dan Biaya telfon

sebesar Rp. 50.000. Berdasarkan data yang diterima dari Perusahaan Elang Sederhana.

Kemudian dalam pengelolaan persediaan oleh perusahaan terdapat pula biaya penyimpanan. Biaya ini terjadi karena adanya bahan baku yang tersimpan digudang. Dalam hal ini biaya penyimpanan yang terdapat pada Perusahaan Elang Sederhana dapat dilihat pada tabel sebagai berikut:

\begin{tabular}{|l|c|c|c|}
\hline \multicolumn{1}{|c|}{ Jenis Biaya } & Harga & $\begin{array}{c}\text { Persediaan } \\
\text { BB (Kg) }\end{array}$ & $\begin{array}{c}\text { Bia.penyim } \\
\text { Unit }\end{array}$ \\
\hline $\begin{array}{l}\text { Pemeliharaan 1 } \\
\text { Tahun }\end{array}$ & 1.8juta & 2.750 & Rp 3.345 \\
$\begin{array}{l}\text { Biaya Listrik 1 } \\
\text { Tahun }\end{array}$ & 3.6juta \\
$\begin{array}{l}\text { Biaya Gaji } \\
\text { Pelaksana gudang }\end{array}$ & 3.6juta & & \\
\hline Total & 9juta & & \\
\hline
\end{tabular}

Biaya Penyimpanan Bahan Baku Sagu Rumbia, diketahui biaya penyimpanan per unit sebesar Rp 3.345,00 yang diperoleh dari pembagian total biaya penyimpanan sagu rumbia dibagi dengan persediaan bahan baku sagu rumbia.

Dari keterangan data yang telah disajikan mulai dari jumlah pembelian bahan baku, jumlah pemakaian bahan baku, biaya pemesanan dan biaya penyimpanan sagu rumbia, maka perhitungan Economic Order Quantity (EOQ) untuk bahan baku sagu rumbia di Perusahaan Elang Sederhana sebagai berikut:

$$
\begin{aligned}
& \text { EOQ }=\sqrt{\frac{2 D S}{h}} \\
& \text { EOQ }=\sqrt{\frac{2(155.500 \times 3.200 .000)}{3.345}} \\
& \text { EOQ }=\sqrt{297.519 .000} \\
&=17.248,7 \mathrm{~kg}=\text { dibulatkan } 17.249 \mathrm{~kg} \\
& \text { atau } 690 \text { karung }
\end{aligned}
$$

Berdasarkan perhitungan bahan baku menggunakan metode EOQ, diperoleh pemesanan bahan baku yang optimal adalah $4.312 \mathrm{~kg}$ atau 172 karung sagu rumbia setiap kali pesan.

$$
\begin{aligned}
& \text { Frekuensi Pembelian }= \frac{155.500}{17.249} \\
&=9,1 \quad \text { (dibulatkan menjadi } 9
\end{aligned}
$$

kali)

Berdasarkan perhitungan frekuensi pembelian menggunakan metode $E O Q$, diperoleh frekuensi pemesanan yang optimal adalah 9 kali pesan dalam setahun.

Hasil penelitian dan analisis kuantitas pembelian bahan baku dengan menggunakan

\begin{tabular}{|c|c|c|c|c|c|c|}
\hline \multirow[t]{2}{*}{ Thn } & \multicolumn{2}{|c|}{$\begin{array}{l}\text { Kebijakan } \\
\text { Perusahaan }\end{array}$} & \multicolumn{2}{|c|}{$\begin{array}{c}\text { Metode } \\
E O Q\end{array}$} & \multicolumn{2}{|c|}{ Selisih } \\
\hline & $\begin{array}{c}\text { Pem } \\
\text { belia } \\
n\end{array}$ & $\begin{array}{l}\text { Fre } \\
\text { kue } \\
\text { nsi }\end{array}$ & $\begin{array}{c}\text { Pem } \\
\text { belia } \\
n\end{array}$ & $\begin{array}{l}\text { Fre } \\
\text { kue } \\
\text { nsi }\end{array}$ & $\begin{array}{l}\text { Pem } \\
\text { beli } \\
\text { an }\end{array}$ & $\begin{array}{c}\text { Freku } \\
\text { ensi }\end{array}$ \\
\hline 2017 & $\begin{array}{l}4.960 \\
\mathrm{~kg} / 1 \\
98 \\
\mathrm{karu} \\
\mathrm{ng}\end{array}$ & 36 & $\begin{array}{c}17.2 \\
49 \mathrm{~kg} \\
/ 690 \\
\mathrm{karu} \\
\mathrm{ng}\end{array}$ & 9 & $\begin{array}{c}12.2 \\
89 \mathrm{k} \\
\mathrm{g} / 49 \\
1 \\
\mathrm{karu} \\
\mathrm{ng}\end{array}$ & 27 \\
\hline
\end{tabular}
metode Economic Order Quantity (EOQ) memperlihatkan terjadi perbedaan kuantitas dan frekuensi pembelian bahan baku tepung terigu. Selisih yang terjadi bisa disebut sebagai penghematan yang seharusnya dilakukan oleh perusahaan.

jumlah pembelian bahan baku sagu rumbia pada tahun 2017 dengan menggunakan kebijakan perusahaan untuk satu kali pemesanan sebesar $4.960 \mathrm{~kg}$ dengan frekuensi sebanyak 36 kali. Kebijakan ini kurang efektif bila dibandingkan dengan menggunakan metode Economic Order Quantity (EOQ). Jika menggunakan metode EOQ akan menghasilkan selisih pembelian bahan baku sagu rumbia sebesar $12.289 \mathrm{~kg}$ dan frekuensi pembelian sebanyak 27 kali. Dengan terdapatnya perhitungan pembelian bahan baku sagu rumbia menggunakan metode Economic Order Quantity (EOQ) akan 
mendapatkan pembelian yang optimal. Kuantitas pesanan optimal sama dengan biaya penyimpanan. Untuk mengetahuinya dapat menggunakan rumus :

$$
\begin{gathered}
\frac{D}{Q} S=\frac{Q}{2} h \\
\frac{155.500}{17.249} \times 3.200 .000=\frac{17.249}{2} \times 3345
\end{gathered}
$$

$(=) 28.848 .049=28.848 .952$

Berdasarkan perhitungan kuantitas pesanan dan biaya penyimpanan bahan baku, diperoleh hasil yang sama. Artinya, kuantitas pesanan optimal sama dengan biaya penyimpanan minimal.

Perusahaan Elang Sederhana dalam melakukan kegiatan usaha harus menghindari dari keterlambatan pengiriman bahan baku sagu rumbia atau ancaman gagalnya pengiriman dengan menyiapkan persediaan pengaman (safety stock). Untuk menhitung safety stock diperlukan data pemakaian maksimum dalam satu tahun,kemudian pemakaian rata-rata dan lead time. Tabel 4.2 merupakan Pemakaian Bahan Baku sagu rumbia dapat diketahui bahwa pemakaian maksimum sebesar $15.000 \mathrm{~kg}$ dan pemakaian rata-ratanya adalah 12.958 dengan lead time 2 hari.

Safety Stock = (pemakaian maksimum pemakaian rata-rata)x $\mathrm{LD}$

$=(15.000-12.958) \times 2=4.084 \mathrm{~kg}$
Persediaan pengaman sagu rumbia yang harus selalu ada pada Perusahaan Elang Sederhana dalam satu bulan adalah $4.084 \mathrm{~kg}$.

Untuk waktu pemesanan kembali (reorder point) bahan baku sagu rumbia menggunakan metode Economic Order Quantity (EOQ) dibutuhkan agar penerimaan pesanan bahan baku tepat waktu dan sesuai. Reorder Point (ROP) adalah waktu dimana pada titik tertentu harus diadakan pemesanan kembali bahan baku sagu rumbia pada Perusahaan Elang Sederhana. Perhitungan reorder point sebagai berikut:

Reorder Point $(\mathrm{ROP})=(\mathrm{LD} \times \mathrm{AU})+\mathrm{SS}$

$$
=(2 \times 431)+4.084
$$$$
=4.946 \mathrm{~kg} \text { atau } 198
$$

karung

Hasil perhitungan safety stock dan reorder point bahan baku sagu rumbia pada Perusahaan Elang Sederhana menggunakan metode Economic Order Quantity (EOQ), Dapat di lihat pada tabel berikut :

\begin{tabular}{|l|l|l|}
\hline Tahun & Safety Stock & Reorder Point \\
\hline 2017 & $4.084 \mathrm{~kg}$ & $4.946 \mathrm{~kg}$ \\
& & \\
\hline
\end{tabular}
dimiliki untuk bahan baku sagu rumbia adalah sebesar $4.084 \mathrm{~kg}$. Kemudian untuk reorder point pada saat bahan baku sagu rumbia yang berada digudang adalah senilai $4.946 \mathrm{~kg}$.

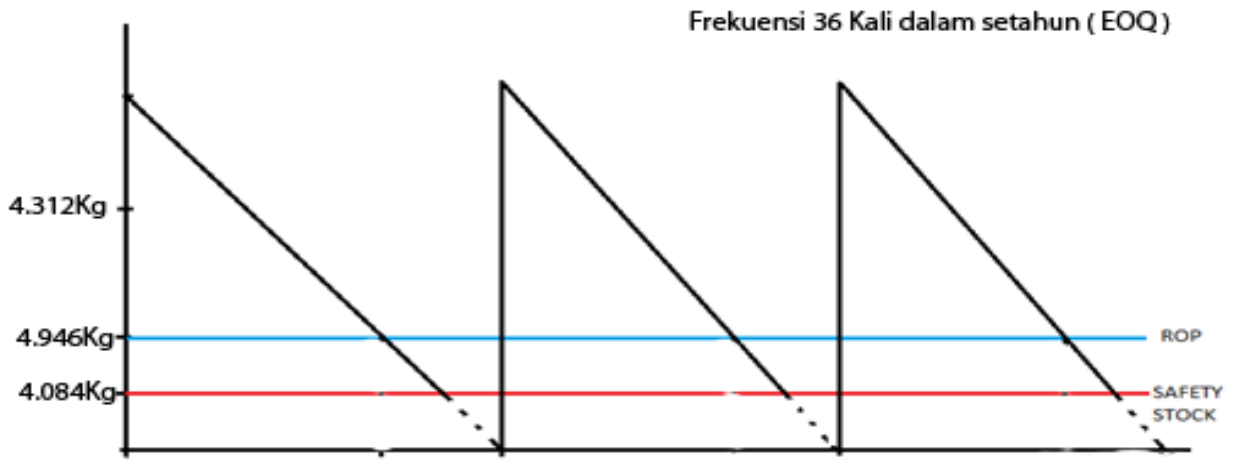

biaya persediaan bahan baku tepung terigu dapat dihitung menggunakan formulasi Total Inventory Cost (TIC). Berdasarkan metode $E O Q$, perhitungan total biaya persediaan bahan baku sagu rumbia di Perusahaan Elang Sederhana sebagai berikut:

$T I C(E O Q)=\sqrt{ } 2 . \overline{D . S . H}$ $=\sqrt{2 \times 155.500 \times 3200.000 \times 3.345}$

$=$ Rp. 57.697.002

Berdasarkan perhitungan Total Inventory Cost (TIC) bahan baku Sagu Rumbia menggunakan metode EOQ dapat diketahui bahwa TIC bahan sagu rumbia tahun 2017 adalah $\mathrm{Rp}$. 57.697 .002 
Untuk perhitungan TIC bahan baku sagu rumbia yang dilakukan Perusahaan Elang Sederhana menggunakan metode konvensional dapat dilihat sebagai berikut:

$T I C=($ total biaya penyimpanan $)+(\mathrm{P})(\mathrm{F})$

$$
\begin{aligned}
& =(9.000 .000)+(3.200 .000)(36) \\
& =R p 124.200 .000
\end{aligned}
$$

Berdasarkan perhitungan Total Inventory Cost (TIC) bahan baku sagu rumbia menggunakan metode konvensional pada Perusahaan Elang Sederhana didapatkan bahwa pada tahun 2017 perusahaan mengeluarkan TIC sebesar Rp 124.200.000

Perbandingan hasil Total Inventory Cost (TIC) bahan baku sagu rumbia yang menggunakan metode konvensional dan menggunakan metode Economic Order Quantity (EOQ) dapat dilihat pada Tabel berikut:

\begin{tabular}{|l|c|c|c|}
\hline Tahun & $\begin{array}{c}\text { TIC metode } \\
\text { konvensional }\end{array}$ & TIC EOQ & Selisih \\
\hline 2017 & 124.200 .000 & 57.697 .000 & 66.503 .000 \\
\hline
\end{tabular}

Sumber : Data perusahaan yang telah diolah

Pada Tabel di atas dapat dilihat selisih diantara Total Inventory Cost (TIC) bahan baku sagu rumbia pada perusahaan antara menggunakan kebijakan metode konvensional dan apabila menggunakan metode Economic Order Quantity (EOQ). Selisih apabila perusahaan menggunakan metode $E O Q$ senilai

Rp 66.503.000

Hal ini menunjukkan bahwa kebijakan perusahaan mengenai total biaya persediaan tidak efisien dalam menghemat biaya. Sedangkan apabila menggunakan metode $E O Q$ maka perusahaan bisa melakukan efisiensi terhadap total biaya persediaan bahan baku sagu rumbia dengan menghemat $\mathrm{Rp}$ 66.503 .000

\section{Kesimpulan}

Berdasarkan hasil penelitian dan pembahasan, telah dapat disimpulkan bahwa penetapan kebijakan pengendalian bahan baku menggunakan metode Economic Order Quantity (EOQ) lebih optimal dan lebih efisien daripada penetapan pengendalian bahan baku dengan metode konvesional yang ditetapkan perusahaan. Hal itu dapat dibuktikan dengan terdapatnya pembelian bahan baku yang optimal dan penghematan Total Inventory Cost (TIC) sebagai berikut: Pembelian bahan baku sagu rumbia perusahaan menggunakan metode konvensional pada tahun 2017 sebesar $4.360 \mathrm{~kg}$ dengan frekuensi pembelian sebanyak 36 kali, untuk total perhitungan Total Inventory Cost (TIC) yang harus dikeluarkan perusahaan pada tahun 2017 adalah sebesar Rp.124.200.000 sedangkan apabila menggunakan metode Economic Order Quantity maka pembelian optimal adalah sebesar $17.249 \mathrm{~kg}$ dengan frekuensi sebanyak 9 kali dalam satu tahun. Dan untuk Reorder Point perusahaan sebesar $4.946 \mathrm{~kg}$. Total Inventory Cost (TIC) konvensional sebesar Rp. 124.200.000 apabila menggunakan metode Economic Order Quantity maka akan menghasilkan Rp57.697.000 sehingga menghemat biaya sebesar Rp. 66.503.000

\section{Saran}

Bagi Perusahaan Elang Sederhana dalam penerapan pengendalian bahan baku sebaiknya menggunakan metode Economic Order Quantity (EOQ). Dengan perhitungan EOQ perusahaan dapat mengoptimalkan persediaan dan dapat mengefisienkan biaya persediaan.

\section{Daftar Pustaka}

Apriyani, Noor. 2017. Analisis Pengendalian Persediaan Bahan Baku Dengan Menggunakan Metode EOQ Dan Metode Konvensional Pada PT Adya Winsa Stamping Industries. Jurnal Opsi Vol 10 No 2. Yogyakarta. FTI

Universitas Pembangunan Nasional "Veteran".

Arikunto, Suharsimi. 2010. Prosedur Penelitian Suatu Pendekatan Praktek. Jakarta: Rineka Cipta.

Deanta, Rifqi. 2012. Efisiensi Biaya Pengendalian Bahan Baku Menggunakan Metode Economic Order Quantity (EOQ) pada PT. Sari Warna Asli V Kudus. Skripsi. Semarang : Fakultas Ekonomi unnes.

Handoko, T. Hani. 2000. Dasar-dasar Manajemen Produksi dan Operasi. Yogyakarta: BPFE. . 2010. Menejemen Personalian dan Sumber daya Manusia,Edisi ke dua.Yogyakarta: BPFE. 
Harris F.W. 1915. EOQ. New Jersey : Wilson.

Hasibuan, Malayu S.P. 2016. Manajemen. Edisi Revisi. Jakarta: Penerbit PT Bumi Aksara.

Heizer, Jay dan Barry, Render. 2010.

Operations Management: Manajemen Operasi. Buku 2. Edisi Kesembilan. Jakarta: Salemba Empat.

Operations Management: Manajemen Operasi. Jakarta: Salemba Empat. 2014.

Operation Management Sustainability from FE 132 at Universitas Indonesia. Jakarta: Salemba Empat

Herjanto. (2013:2). Menejemen Operasi, Edisi 3.Jakarta: Salemba Empat.

Indrajit, R.E dan R. D Pranoto. 2003:

Manajemen Persediaan. Jakarta: PT

GramediaWidiasarana Indonesia.

Katiandagho, Simbar, Baroleh Lolowang. 2014. "Analisis Pengendalian Persediaan Bahan Baku Cepaka Pada Industri Mebel Dengan Menggunakan Metode EOQ (Studi kasus pada UD. Zaman Batu).

Jurnal Ekonomi Bisnis Vol 5, No 3. Sulawesi Utara : Fakultas Ekonomi Universitas Sam Ratulangi.

Kotler, Philip and Gary Armstrong. 2012. Prinsip-prinsip Pemasaran. Edisi. 13. Jilid 1. Jakarta: Erlangga.

Nafirin, M. 2004. Penganggaran Perusahaan. Edisi Revisi. Jakarta: Salemba Empat.

Ristono, Agus. 2013.Manajemen Persediaan. Yogyakarta : Graha Ilmu.

Slamet, Achmad. 2007. Penganggaran Perencanaandan Pengendalian Usaha. Skripsi. Semarang : Fakultas Ekonomi unnes.

Stevenson, W.J., Chuong, S.C. 2014. Manajemen Operasi Perspektif Asia, Edisi 9. New Jersey : Prince Hall.

Stevenson, William J. dan Chee Chuong, Sum. 2014. Manajemen Operasi Perspektif. New Jersey : Prince Hall.
Sujarweni, Wiratna. 2015. Metodelogi Penelitian Bisnis Dan Ekonomi. Yogyakarta : Pustaka Baru Press.

Tipaka,Yulin. 2017. Analisis Pengendalian Persediaan Bahan Baku Bunga Krans Pada Usaha Bunga Plastik Dengan Menggunakan Metode Economic Order Quantity Dan Metode Economic Production Quantity. Jurnal Ilmiah Sains Vol. 17 No. 2. Sulawesi Utara : Fakultas Ekonomi Universitas Sam Ratulangi.

Usman, Husaini. 2010. Manajemen: teori, praktik \& riset pendidikan. Jakarta: Bumi Aksara.

Zakaria, Feby. 2014. Pengendalian Persediaan Bahan Baku Pasir Silika Menggunakan Metode EOQ Studi pada CV. Bumi Silika Jaya. Jurnal Ilmiah Sains. Malang : Fakultas Ekonomi Universitas Brawijaya. 